\title{
INCENTIVE PROBLEMS IN THE CENTRALLY PLANNED ECONOMY OF HUNGARY
}

\author{
LAJOS HÉTHY and CSABA MAKÓ
}

$\mathrm{T}$ HE Hungarian economic reform, introduced in 1968, has been properly considered a major shift from centralization to decentralization, representing perhaps the most radical postwar change in the economic model of any Eastern European country. It is obvious, however, that the functioning of a traditional economic system cannot be basically changed from one day to the next: obstacles to the operation of the new model in Hungary had been accumulating for about two decades and still exist, both in the economy and the society. The purpose of this article is to describe some of the difficult aspects of the period of transition.

After having experienced a dynamic period of extensive industrialization, in 1968 Hungary substituted for its strongly centralized model of planned economy a

The goal of the Hungarian economic reform of 1968 was to accelerate the growth of industrial productivity by providing managers with more authority in planning and administering the operations of their companies. Direct and detailed instructions by central agencies were replaced by general central regulations. One aim of the new economic model was to encourage better performance by workers through the introduction of improved money incentives. This objective has not been achieved yet, for work discipline and work intensity remain loose in many enterprises. This article examines work performance and incentive plans in three companies in an effort to identify the socioeconomic conditions and influences responsible for their difficulties in improving work performance.

Lajos Héthy and Csaba Makó are members of the Institute of Sociology, Hungarian Academy of Sciences.-EDITOR less centralized one, which was somewhere between the centralized and decentralized extremes. The change was carried out on the proposition that the major lines of structural development and income distribution should be planned by central agencies, but a market system should be created which would permit decentralized determination of methods of carrying out the program. The distribution of disposable income between major occupational and income groups was to be determined by the central agencies; total fixed investment in the economy and the shares to be directed to a few specific growth sectors and to major areas of social investment were to be decided by the central authorities; but the distribution of the remainder of investment and the distribution of income within the central limits would be determined by the economic organizations and by the market.

The carefully prepared program, aimed at intensive development by accelerating the growth of industrial productivity, brought increased independence for economic organizations; it replaced direct and detailed instructions by central agencies with indirect and comprehensive central regulations, giving more power to managers in formulating the strategy of their companies. Thus, the permanent intervention of central organs was replaced, at least partially, by the orienting role of a somewhat 
liberalized market and by the introduction of profit incentives for managers. The labor market also experienced relaxation of restraints. ${ }^{1}$

In the previous model the central agencies had the staggering tasks of setting prices arbitrarily; investigating all production possibilities and determining the package to be chosen; and ensuring that the managers actually followed instructions. This practice greatly promoted industrialization but seriously impaired efficiency. Since 1968, some prices have continued to be centrally fixed, but others have been limited only in range, while the remainder have been allowed to change market conditions. Managers have been given more authority in choosing a profit-maximizing package from their production-possibility set, although certain aspects of their activities have remained under strict control, such as decisions concerning the level of wages. Profits have been introduced as the most important indicator of the efficiency of organizations, and as an incentive for managers, a share of profits has been turned into differential incentive bonuses. Workers, whose movements were strictly limited in the previous model, have had complete freedom to choose jobs for themselves. In short, the new system is intended to give impetus to the initiative of individuals and groups engaged in production and to free the central agencies from concern with the details of the economy which determine

\footnotetext{
${ }^{1}$ In the $1950 \mathrm{~s}$ the dynamic process of industrialization was based on agriculture: it pumped surplus farm labor into factories and profits accumulated by farms into industrial investments. Industrial growth resulted mostly from the increase in manpower, with only very slight technological progress. Complementary investments and maintenance were neglected. Then in the $1960 \mathrm{~s}$, the reserves of agriculture were exhausted.
}

neither its structure nor the pace of its general development.

\section{Labor Efficiency}

The positive effects of the new model have been felt in the economy; however, at the same time, the serious difficulties in work efficiency, which prevailed under the former model, have continued. Discipline in the work place has remained poor, and work intensity continues to be loose in many state-owned companies. Therefore, several attractive theoretical and practical problems have emerged for economists and sociologists to discuss. To what extent can current difficulties in work performance be attributed to the heritage of the previous model in the internal structure and in the general socioeconomic circumstances of economic organizations? More generally, what structural obstacles have to be overcome by a new model so that its maximum positive effects may be felt? To what extent are possible contradictions and rigidities in the new model responsible for the existing difficulties, and what is the relationship of these negative features to the heritage of the past?

Although it is beyond our ken to answer these questions fully, we have tried to contribute to their clarification by a sociological investigation, which was started in 1968 and has since been completed. We have focused our attention on only one target of the new model-the introduction of more efficient money incentives for workers to encourage better performance. In the course of our research, the progress and the obstacles to realization of this incentive program have been examined in three state-owned engineering companies. ${ }^{2}$

"This article presents a second analysis of the same topic by the authors. In contrast to the present focus on macro-socioeconomic factors, 


\section{Objectives and Methods}

In our investigation we have undertaken the following tasks: to judge the relative level of efficiency of the incentive systems $(E)$ at the three companies since 1968; to examine the relationship between $E$ and those socioeconomic factors in the internal structure and the outside environment that might have had an effect on the incentive systems at these three companies; and to investigate (among the factors of outside environment) the role of the central regulations that have come into existence as part of the new economic model.

Our approach to $E$ was in line with scientific management motivation theory. Despite our awareness of its shortcomings, we have found it a source of inspiration. Our standpoint on incentive systems was that an obviously poorly formulated wage plan can never be a success, although a seemingly perfect incentive system can sometimes be a failure.

In Hungary the practice of the Stakhanovist movement in the $1950 \mathrm{~s}^{3}$ and our own investigations carried out in 1969-71

the previous article examined micro factors within one company. It serves as a basis for some statements in the present article. See Lajos Héthy and Csaba Makó, "Obstacles to the Introduction of Efficient Money Incentives in a Hungarian Factory," Industrial and Labor Relations Review, Vol. 24, No. 4 (July 1971), pp. 541-553.

${ }^{3}$ The flagrant injustices in wages and the arbitrarily created privileges, however, resulted in grave conflicts among workers and between workers, on one hand, and trade union, party, and management on the other. Stakhanovists usually were arbitrarily created "heroes of work," often producing their outstanding individual production results with the help of several disguised assistants and by other means, contradicting fair play. The other workers desperately tried to keep pace with them, but of course they were always lagging behind. It must be mentioned that considerable differences in wages, whether fair or unfair, always lead to conflicts which managers have to face if they endeavor to make incentive systems efficient. have proved the existence of a very high motivational relationship between wages and workers' production. Under such conditions the employment of a straight piece-rate system, if possible, seems to be the best method of motivating labor. To investigate these hypotheses, three companies were chosen with one thing in common: the characteristics of their technological processes made the employment of such incentives rational and possible.

Thus, the relative levels of efficiency of the wage plans in the three organizations have been determined by comparison to a theoretically ideal one. The results also have been checked by the relative levels of work discipline and work intensity, which are important, although indirect, reflections of $E$.

In our approach to the set of socioeconomic factors influencing the companies' behavior in the realization of the incentive program, we have tried to cover as large a sphere as we could. Among the large number of interacting and sometimes overlapping factors, we concentrated our attention on the following important ones: (1) relations of the companies' management and labor force (intramanagement and management-labor relations of powers, workers' attitudes concerning production, etc.); (2) the economic positions of the companies (their market situation, production costs, technological efficiency, state subventions, etc.); and (3) national restrictive measures (central control over wages per capita, the functioning of the profit-sharing system, etc.). In our opinion, the efficiency of wage incentives and the relevant behavior of the companies have always been determined by a specific constellation of the above factors.

Our methods of investigation included an analysis of documents and data from 
the files of the companies, unstructured interviews, and case studies.

\section{Incentive Systems of Different Efficiencies}

A brief description of the three companies follows. Company $A A$ is situated in the mostly agricultural area of western Hungary; it has about 15,000 employees and manufactures railway coaches, tank wagons, differential gears, axles, steering gears, and chassis for trucks and buses. Company $B B$ has its headquarters in the highly industrialized capital of the country; it employs about 5,000 people and produces several thousand types of medical instruments. Company $C G$ is also situated in the capital; it has about 700 workers and produces a special type of electrical instrument.

At Company $A A$, the construction of the incentive system, at least in principle, has been efficient. The workers carry out their tasks mostly in groups and are paid directly on the basis of how much they produce (with the exception of a few departments). For the most part, there is neither a lower limit (guaranteed level) nor an upper limit (ceiling) for wages. The management of the company, however, exercises strict control over piece rates. A series of piece-rate cuts (10.4 percent in 1964, 9.4 percent in $1965,6.9$ percent in 1966, 19.5 percent in 1969 , etc.) seems to have served the purpose of keeping production standards stable. In general, the functioning of the incentive system has been a success for the past few years, although a number of workers have carried out cyclical slowdowns from time to time, and the ratio of labor turnover has been rather high. The negative symptoms have been primarily due to the practice of "constant" piece-rate cuts, which usually have led to restriction of production and other expressions of worker dissatisfaction. In addition, the wage-restricting measures of the company often have lacked a proper basis; they have not been justified by improvements in technology or organization, and they have been directed toward increasing work intensity-at "sweating the people," as the workers put it.

Company $B B$ has preferred a rather irrational type of piece-rate system. Although it is an inherent requirement of motivation to give workers proper possibilities of maximizing production in order to earn maximum money rewards, the management of this company has done just the opposite. It established a lower guaranteed level of wages and production at 80 percent and also introduced an upper limit or degressivity plus upper limit of 100 or 110 percent. Piece rates have been extremely loose for the past decade, and management made the first vague steps to revise them only in 1970 , after the beginning of our investigation. The pseudohumanitarian slogan enunciated by management was "a ceiling on earnings had to be established to defend the workers against themselves, since some workers, in search for profits, were ready to endanger even their own health." But at the same time the management admitted, "conditions are far from being satisfactory in the control of piece rate. At present there is no central organ in the firm that could improve the level of production or standards that are usually very loose, although varying in their level from unit to unit." Poor management naturally results in poor work discipline. A considerable part of working hours has been spent in idle conversation, lunches, and cigarette breaks; and there has been a general practice among workers of making various articles for their own household use. Although these practices have been disapproved of 
by management, disciplinary measures have been rarely and only reluctantly taken against them.

Company $C C$ has rejected use of a piece-rate system, it has preferred day pay. As a result, work intensity has been lower than at Company $A A$, but it has remained higher than at Company $B B$. Workers work at moderate speeds, and discipline has been acceptable. Sharp conflicts have been rare, and the rate of labor turnover has been more favorable than at either of the other two factories.

After having examined the efficiency of payment systems at the three companies, we have come to the following conclusions. Despite the homogeneous aim of the new economic model, there exists a variety of wage plans at stateowned companies, ranging in their efficiency from high to very low. There seems to be a general tendency for restricting the level of wages (by cyclical and radical cuts of piece rates at Company $A A$, by the establishment of a ceiling on earnings at Company $B B$, and by the preference of day pay at Company $C G)$.

\section{Labor-Management Relations}

The introduction and functioning of an incentive system is basically determined by the relations of management and labor and by the intramanagement and management-labor power play within an economic organization. In Hungary, the leadership of an economic organization consists of the leaders of three different organizations: the company, the trade union, and the party organization. All of them have formal rights to influence decisions, although the majority of such rights naturally belongs to the company.

The leaders of Companies $A A$ and $C C$ have had the capacity for building an efficient incentive model. At Company $A A$ the general manager, an autocratic leader, has strict control over the technical-economic administration, a situation which gives him power that cannot be counterbalanced by the trade union or the party. As he put it, he is "shaking the chairs of his department heads all the time, so that the people cannot fall asleep in them." Company $A A$ is considered one of the best organized enterprises in the country. In its traditional departments rationalization of the work process has reached a high level: work groups are maximally specialized, their activities are harmonized, and insufficiencies in the supply of work duties and material and in the maintenance of tools and equipment are practically unknown. The workers have only one duty - to increase production. In its newly established departments, the company employs the most up-to-date methods of programming production. Its personnel department, dealing with labor and wages, is also high above the national standards in its level of efficiency. Its scientific-management-oriented experts have worked out the best possible methods for the motivation of workers, radically substituting new incentive methods for older ones.

At Company $C G$, on the other hand, the leadership seems to be more democratic, but also efficient. The general manager, the heads of the trade union, and party executives make their decisions in close cooperation: there are no rivalries in the "triangle," and the technicaleconomic administration follows the policy of the collective leadership as closely as it does at Company $A A$. The scheduling of jobs, supply of material, and maintenance of tools are good.

Company $B B$, in contrast to the other two enterprises, has a divided leadership. 
The general manager and his deputy are rivals in controlling the technical-economic administration, and both look for the support of either the trade union or the party. Under such conditions of internal conflict, management cannot make supervisors follow its master plan, if indeed there is one. Efficiency is poor. The degree of specialization in and the coordination of the work process are unsatisfactory. Workers are not supplied with the proper amount of job assignments; there are chronic stoppages in the supply of materials; and maintenance of tools has been inadequate. According to the records of foremen, in 1967 there were about sixty days when the majority of workers could not work because of lack of material. The personnel department, dealing with labor and wages, cannot cope with the problems it faces, as indicated by the looseness of piece rates mentioned above. ${ }^{4}$

The quality of management is important in the introduction of an incentive system, since management must overcome serious difficulties. The level of inherited piece rates has been terribly loose in most companies. In the $1950 \mathrm{~s}$ the level of wages had been linked by central regulations to the amount of production. The companies could increase it only if production indices (percentages) increased. Thus to get more money to pay workers, managers postponed or completely neglected necessary piece-rate cuts. ${ }^{5}$

The negative results of the above practice have been eliminated by continuous

\footnotetext{
${ }^{4}$ Perhaps it is worthwhile to mention that the continuation of the Stakhanovist movement and work competitions of the 1950 s were undermined, among other things, by the managers' incapacity to ensure proper environment, continuous supply of duties and material, etc.

${ }^{5}$ This was one of the reasons for the fact that Stakhanovists could sometimes reach such fantastic production results as $1,800-2,000$ percent.
}

piece-rate cuts at Company $A A$ and the abolishment of the piece-rate system at Company $C C$. However, the piece-rate system with its drawbacks continues at Company $B B$.

\section{Characteristics of the Labor Force}

The quality of labor also shows significant differences at the three companies, influencing the workers' responses to money incentives.

Company $A A$, as mentioned earlier, is situated in the center of an agricultural area experiencing rapid progress in industrialization. Its employees are mostly agricultural in origin, living in villages nearby. They are hardworking people, ready to make extra efforts for extra money and aim their activities at maximizing their earnings. In the tradition of the Hungarian peasant's style of life, "rate-busters" are not rare among them. Their behavior also is motivated by the fact that wages mean their most important source of income; their out-of-factory activities to earn money are negligible.

Companies $B B$ and $C C$, on the other hand, are situated in the capital, and their manpower is primarily of industrial origin. The traditions of their industrial past have made these people less responsive to money incentives. Moreover, in the large industrial area of the capital, services are inadequate and repair work is always in demand, netting such workers (sheet-metal workers, electricians, mechanics, etc.) considerable additional (although generally illegal) income.

Geography thus plays an important role in the quality of both management and labor. In addition to the effects noted above, we must mention that the relationship of supply and demand in the labor market is more favorable for Company $A A$ than for the other two enter- 
prises. In the rural areas there are only a limited number of jobs, but in the capital, employees have unlimited possibilities to change jobs.

The situation in the capital has also been aggravated by a reversal in the flow of manpower. In the 1950s, labor was pumped from agriculture into industry, from the most remote parts of the country to the capital. In the 1960 s, after industrialization had been accelerated in the rural areas, and the agricultural cooperatives had been stabilized, many people left Budapest and went back to their villages. Companies in the capital have suffered because of this migration, while it has benefitted factories in the country. Thus the managers of Company $A A$ have held a stronger position of power in relation to labor than managers in the capital.

Other management power relationships have also been affected by location of the enterprise. In a country town the general manager of a large factory is always a key figure in local government. General managers in the capital, on the other hand, are relatively minor figures on the chessboard, since the capital is headquarters for many large enterprises and all national institutions. The quality of management and labor and power relationships throw much light on the problems discussed, but a great part of the companies' behavior still remains obscure. Why has Company $A A$ carried out constant piece-rate cuts, "sweating" its labor, provoking serious internal conflicts, and often making its incentive system counterproductive? How could Company $B B$ exist with such internal conditions, if efficiency were nationally stressed and profits represented as its main indicator? Why has Company $C C$ rejected the piece-rate system, despite favorable technological and organization- al characteristics and the relatively strong position of its management?

\section{The Companies' Economic Position}

The factors discussed above have created possibilities for managers to act to reform their incentive systems or have prevented them from doing so. But they have not motivated them. Motivation has been provided by profit incentives (an issue to be discussed later) and by the overall economic position of the enterprises.

On the basis of various macro conditions, the managements of the three companies have been subjected to pressures of varying force in their search for profits and efficiency. The question is whether outside influences have been able to outweigh the managers' reluctance to upset the existing relations of interests and powers within their organizations by reforming wage incentives and changing the financial positions of groups, thus possibly provoking serious conflicts.

The management of Company $A A$ has been forced, by the nature of its products, to use prices in the international market as a guide and has tried to choose a profit-maximizing package in its production-possibility set. The decision was made to cease manufacturing railway coaches and undertake production of heavy-duty diesel engines for buses and trucks. The company's technology was too antiquated to make railway coach manufacturing profitable, and state subsidies were being withdrawn. In addition, demand for coaches was limited, and several other companies produced them under more favorable technological circumstances. However, immediate cessation of production was not possible; withdrawal took the form of gradual reduction of output. Accordingly, manage- 
ment felt that cuts in production costs were necessary. Since investment in new equipment was not indicated under the circumstances, it decided to reduce labor costs. The method selected was to encourage workers to make more intensive efforts by the help of a radical piece-rate system. This has been a difficult procedure for these managers to follow, since they have had to confront the natural resistance of workers, but they have had no other choice.

Company $B B$ has been in a more favorable position. Although the scheduling of jobs, the maintenance of tools, the supply of material, and the technology are all inadequate-that is, the entire production operation should be unprofitable, according to the standards of the international market-the company can still attain rather high profits. This has been possible primarily because of its monopolistic position in the home market and control over prices. Second, its products (medical instruments) are considered to be of "great necessity for the country," and it therefore enjoys large state subsidies. Consequently, management has taken few steps toward rationalization of the work process and has not been hasty in establishing radical wage incentives for the workers. It has been engaged more in "manipulating" profits than in increasing efficiency. Management's lack of interest in efficiency has been an important factor in the creation of the distorted form of a piece-rate system with its upper ceiling on earnings. The established lower limit (guaranteed level), on the other hand, has served as a defense of the workers against the likely negative effects on earnings of insuffciencies in the supply of material and of poor maintenance. It has provided a comfortable position for the leadership of the company. ${ }^{6}$

Company CC's position in the home market is also a monopolistic one, and it can sell its products (special electrical equipment) on favorable terms in the world market as well. Also, fixed prices have been set for them in the home market. The company is relatively new, wellorganized, and equipped with modern means of production, thus ensuring high efficiency even at a medium level of work intensity and discipline. The management has not been interested in motivating labor more radically; rather, it has concentrated on innovations in technology, on sales, on more favorable market terms, etc.

The economic position of the companies, as an important factor in motivating managers to introduce efficient incentives for labor, however, cannot be discussed separately from the role of certain restrictive measures by the national government.

\section{Government Restrictions}

The government has urged the introduction of efficient wage incentives, but at the same time, by its restrictive regulations, has made realization of this goal difficult, sometimes practically impossible.

The central agencies have strict control over wages per capita at all stateowned companies and have set them on a roughly uniform level in all factories. The aim is to avoid certain possible negative by-products of the new economic model: first of all, the possibility of joblessness. Joblessness is unknown in Hungary, but a price is paid in low output per worker. Central control over per capita wages prevents companies from

\footnotetext{
${ }^{6}$ Internal clashes and rivalries in management do not seem unrelated to this "comfortable" position.
} 
employing smaller well-paid work forces stimulated by adequate wage differentials. Instead managers are required to employ larger medium-paid work forces which are not properly motivated. If a company wants to increase production, it cannot pay extra money to its (often idle) workers but instead must look for additional manpower.

The trade union, because of its heritage and present structure, cannot undertake the task of protecting the workers. It has united all sorts of employees in its ranks and leadership, from manual workers to middle and top management. It has no clearly outlined goals, based on realistic considerations of the present relations of interests and powers within the companies. The necessary national "centralization" of the defense of workers' interests is one of the main contributors to the present state of wages.

According to the central regulations, even a very slight increase in wages per capita is very heavily taxed: it has to be covered by the share of profits to be turned into incentive bonuses. But this part of the profit is usually so low that the sum spent on wage increases (extracting all profits from managers) can have only negligible results, and any further increase can make the company "bankrupt." For example, at Company $A A$, the share of profits to be divided in 1968 meant a ten-days' pay for the workers and about forty-days' pay for the managers. Thus the companies that have to achieve their growing production targets must invest in technical equipment, improve their organization, and attract additional manpower, resulting in a large artificial demand for workers in the labor market. In addition, the flourishing agricultural and industrial cooperatives, which have remained untouched by central measures of wage restriction, have produced a demand for workers. Thus a curious situation has developed. The large state-owned companies, often wellequipped, well-organized, and highly productive, cannot rival the small, poorly equipped, poorly organized enterprises in the labor market. The best skilled workers depart from the factories and take jobs at the cooperatives that can pay often twice as much as big companies.

To avoid misunderstanding, it must be mentioned that the financial situation of the state-owned companies, in general, is not worse than that of the cooperatives. They can offer several conveniences to the employees, which cooperatives cannot (i.e., workmen's hostels, restaurants, washing rooms, sports fields, etc.). But workers seem to be much more interested in obtaining income directly in wages than indirectly through benefits.

The big companies, tied by regulations and at the same time pressed by the high rate of labor turnover, desperately try to cope with the situation. They work out various (often illegal) solutions to break through the fixed level of wages, but these efforts usually fail. The companies may increase minimum wages, but at the same time (the average being fixed), they have to decrease maximum wages. As a result, the scale of wage differentials becomes even narrower; this hurts the skilled workers, and the lack of proper wage differentials undermines the functioning of the wage plan. Under such conditions no wage plan can work effciently.

\section{Management's Dilemma}

The contradiction between management's desperate efforts to stimulate labor and its need to maintain the fixed level of wages per capita is best manifested in the case of Company $A A$. This contradictory policy contributes to the 
inconsistent features of the company's incentive measures and to the practice of constant and usually unjustified piecerate cuts. The same frustration of the fixed level of wages also has contributed to the existence of the pseudoefficient wage plan of Company $B B$ (with a ceiling on earnings) and to the complete rejection of a piece-rate system by Company $C C$.

In economic terms, the centrally set level of wages per capita fluctuates around the "minimum shutdown point" and "maximum shutdown point" at the same time. It fails to attract labor, but it increases the risk of the company becoming "bankrupt."

Of course, shutdown in a centrally planned model cannot be understood in its original sense. The breaking of central regulations endangers not so much profits as the position of managers, who (if they can do so, as in the case of Companies $B B$ and $C C$ ) refrain from the hopeless effort of building up a really efficient wage plan for labor.

The crucial question is, why do the central agencies set wages per capita on roughly the same level at all engineering companies; why is the share of profits to be divided so low?

It is obvious that the establishment of proper wage differentials among the workers requires, because of the inherent logic of the system, proper differentiation of the level of wages per capita among the companies as well.

Wage differences in labor must be based, in principle, on the work done. Differences between the wage levels of companies theoretically must be based on efficiency. But the trouble is that efficiency (resulting not so much from the activities of managers and workers but from the past arbitrary decisions of central organs) has to be, at least for the moment, excluded from consideration. ${ }^{7}$ But no other reliable indicator exists. That is why the sum of incentive bonuses from profits also has had to be limited. Furthermore, that is why the managers' incentive bonuses have not been consistent with the companies' production and profit achievements and have been kept small, giving little incentive to managers who have usually endeavored to score only "relatively good," "acceptable," or "generally satisfactory" results. The present obstacles to increased efficiency, the insufficiencies of money incentives, the unreliability of a profit indicator, the fear of social injustices and conflicts, the restrictive measures on wages and profits to be divided, in a sense, seem to create a vicious circle, the breaking of which is an enormous task for the future.

Thus, even if managers sought an optimum solution in wage incentives, it could not result in an efficient system. But as managers naturally have sought only a satisfying, acceptable solution, the efficiency of wage plans has become even worse.

\section{Conclusions}

On the basis of the limited survey reported here, we are unable to analyze the effects of the new decentralized economic model on the behavior of managers and

\footnotetext{
${ }^{7}$ This practice naturally discourages the managers of the best companies. One of them told us, "We put different sums of money into the common pool, and we have to take out equal ones from it." This problem is compounded by the other difficulties resulting from the necessary cooperation of more and less efficient enterprises. Company $A A$ is in a relatively favorable position, because it has developed into a large vertical factory, having its own metallurgical department, etc., but the work of other companies is often thwarted by late deliveries of components or deliveries in poor condition. Company $B B$, in that respect, is in the worst position since it manufactures several thousand types of products putting it in a jungle of cooperational diffculties.
} 
business organizations in general. ${ }^{8}$ We have omitted several important areas of company activity (investments, trading, financial transactions), so we might focus our attention on the relatively narrow problem of the introduction of efficient incentive systems. A few observations on the overall operation of the reform may be offered. During the first two years of the new economic model, the central regulations could not adapt themselves flexibly enough to the different microand macro-socioeconomic circumstances of the various companies (technology, organization, internal power structure, market position, price policy, etc.). The phenomenon is best manifested in the uniform level of wages per capita set for the companies. The central regulations could not be adapted quickly enough to the constantly changing circumstances. The phenomenon is best indicated by the companies' wage level moving around the maximum and minimum "shutdown points" at the same time. The central regulations have not been coordinated properly (as in the case of wage control over state-owned companies and cooperatives).

In addition to the insufficiencies of central regulations, the heritage of the past, the level of the organization of work, backward technology, the backward and sometimes unprofitable structure of products have also meant serious obstacles to the introduction of workable and productive wage plans, illustrating

\footnotetext{
${ }^{8}$ An analysis of the Hungarian economic reform has been recently completed by David Granick of the University of Wisconsin for the International Development Research Center at Indiana University. The paper, from the economist's point of view, contributes significantly to the authors' argument in this article.
}

that the transition from a less efficient centralized model to a more efficient decentralized one is a long and painful process.

Our results have also shown that the establishment of proper incentives for managers is a serious problem even in the new model of the economy.

The conflict of efficiency and humanitarianism seems to remain existent even in the decentralized economic model. The central regulations have contributed greatly to the failure of wage incentives, although they have protected workers against joblessness and other possible negative effects of the acceleration of productivity. In this regard they are a success in the short run. In the long run, however, the present humanitarian preferences would seem to undermine the efficiency which is the main guarantee for achieving the humanitarian goals.

Radical changes in the economic system of Hungary have to face serious natural obstacles because of the heritage of the past and the restraints of the present. Critical restraints on progress include the rejection of the possibility of unemployment, rapid increases in consumer prices, and the exclusion of any other form of pressure placed on important social groups including labor and managers. But neither the heritage of the past nor the restraints of the present should become absolute; within the given limits there is possibility to make further steps forward. To decrease the negative by-products of the decentralized model, it seems necessary to make central regulations more differentiated, more flexible, more coordinated, and above all, scientifically better founded on analysis of the functioning of economic organizations. 